\title{
Synergistic interaction effect between job control and social support at work on general psychological distress
}

\author{
BongKyoo Choi $\cdot$ Per-Olof Östergren · \\ Catarina Canivet • Mahnaz Moghadassi • \\ Sara Lindeberg • Robert Karasek • Sven-Olof Isacsson
}

Received: 3 December 2009 / Accepted: 8 June 2010 / Published online: 26 June 2010

(C) The Author(s) 2010. This article is published with open access at Springerlink.com

\begin{abstract}
Purpose Little is known about the interaction between job control and social support at work on common mental disorders. To examine whether there is a synergistic interaction effect between job control and social support at work on general psychological distress and whether it differs by the level of job demands.

Methods About 1,940 male and female workers from the Malmö Shoulder and Neck Study were chosen for this cross-sectional study. Job control, social support at work, and job demands were measured by the Swedish version of the Job Content Questionnaire, and general psychological distress was assessed by the General Health Questionnaire. Results A significant excessive risk increase for general psychological distress was observed when workers had
\end{abstract}

\section{B. Choi $(\bowtie)$}

Center for Occupational and Environmental Health,

University of California Irvine, 5201 California Avenue,

Suite 100, Irvine, CA 92617, USA

e-mail: b.choi@uci.edu

P.-O. Östergren · C. Canivet · M. Moghadassi $\cdot$ S. Lindeberg

Division of Social Medicine and Global Health,

Department of Clinical Sciences, Malmö,

Lund University, Lund, Sweden

\section{S.-O. Isacsson}

Division of General Practice,

Department of Clinical Sciences, Malmö,

Lund University, Lund, Sweden

R. Karasek

Department of Psychology,

University of Copenhagen, Copenhagen, Denmark

R. Karasek

Department of Work Environment,

University of Massachusetts Lowell, Lowell, MA, USA both low job control and low social support at work in both men and women. The synergistic effect was stronger in women, when job demands were low (Rothman's synergy index was 2.16 vs. 1.51 when job demands were high). However, in male workers, while a strong synergistic effect between job control and social support at work was found when job demands were low (synergy index was 9.25), there was an antagonistic effect when job demands were high (synergy index was 0.52 ).

Conclusions There was a synergistic interaction effect between job control and social support at work on general psychological distress, but the synergistic effect or its effect size differed by the level of job demands and gender. An atomic, additive approach to the risk assessment of the psychosocial work characteristics on common mental disorders could be misleading or lead to a risk underestimation.

Keywords Swedish · Job demands · Psychosocial · Work $\cdot$ Synergy index

\section{Introduction}

Common mental disorders (i.e., mild to moderate depressive and anxiety disorders, Stansfeld and Candy 2006) at workplaces have imposed economic and social burdens on the whole society as leading factors of increasing sickness absence and disability cost in Western industrialized countries (Beck and Koenig 1996; Houtman 2005; NIOSH 2004; Schaufeli and Kompier 2001). Adverse psychosocial work characteristics such as low job control, high job demands, and low social support at work have been reported as risk factors for poor mental health in several longitudinal epidemiological studies (Bültmann et al. 2002; 
Marchand et al. 2005; Niedhammer et al. 1998; Stansfeld et al. 1998, 1999; Wang and Pattern 2004).

However, relatively little is known about whether the combined risk of the three adverse psychosocial work characteristics for common mental disorders is additive (i.e., a simple sum of its components' risks), or if they act as effect modifiers for each other [synergistic (i.e., greater than the simple sum), or antagonistic (i.e., less than the simple sum)]. In particular, the following questions have been rarely asked: whether there is a meaningful interaction between job control and social support at work on common mental disorders; and whether the interaction will differ by the level of job demands. For instance, recent meta-analyses about psychosocial work characteristics and common mental disorders are mute to the above questions (Bonde 2008; Netterstrøm et al. 2008; Stansfeld and Candy 2006).

These questions are important for accurate risk assessments (Rothman 1986; Thompson 1991) of the psychosocial work characteristics for common mental disorders, for instance, the combined risk of the psychosocial work characteristics could be substantially underestimated under the additive assumption. In addition, they are essential in terms of targeting of intervention (Thompson 1991), for instance, the benefit of an intervention (i.e., eliminating a risk factor) could be greater in those who are subject to multi-risk factors under the synergistic assumption. Furthermore, they would be informative in understanding complex mechanisms of the psychosocial work characteristics to common mental disorders as well as evaluating contemporary job stress models.

Job stress models and the interaction between job control and social support at work

Some contemporary work stress models such as the demand-resource (DR) models (de Jonge and Dormann 2003; Demerouti et al. 2001) and demand-control-support (DCS) model (Johnson and Hall 1988; Karasek et al. 1982) include job control and social support at work as their key concepts. Nonetheless, none of them propose a specific hypothesis on the relationship between job control and social support at work with regard to health outcomes. Although job control and social support at work are each regarded as the component of resources in the DR models to meet job demands, no due attention is given to the nature of the interaction (i.e., additive vs. non-additive) between the resources on health outcomes. The DCS model was developed by incorporating social support at work into the demand-control (DC) model (Karasek 1979). However, the focus of the model is the interaction between social support at work and job strain (as one variable consisted of job control and job demands, usually dichotomized for analysis into high and low strain) on health outcomes. As a result, the interaction effects between job control and social support at work and between job demands and social support at work on health outcome become the out-of-focus areas in the model.

Johnson (1991) came up with a new theoretical concept, collective control, a synthesis of the two concepts of job control and social support at work that had been studied separately, which is also in line with the idea of Gardell (1982, p. 35): "By combining collective influence in management decision making with the formation of autonomous groups...the individual and the group will be able to achieve enlarged control over the work system and the work methods." The concept, collective control, emphasizes a dialectical interrelationship between job control and social support at work [as a property of a group of workers-workers' solidarity-against managerial control (Aronsson 1989; Grzyb 1981)]. Collective control could be related with workers' health in various ways (Johnson 1991), for instance, it can alter the level of job demands directly (eg. through a collective bargaining), modify the detrimental health impact of job demands (eg. provision of emotional support), or affect workers' health through fulfilling basic human needs such as companionship and need for control, independent of job demands.

The collective control concept implies that there could be a synergistic interaction between job control and social support at work on common mental disorders. However, the concept does not allow a testable prediction as to whether, if any, the synergistic interaction will differ by the level of job demands. With regard to the nature of the interactions in the DCS model, Kasl (1996) also argued to test and present all possible interactions between job control, job demands, and social support at work on health outcomes. Furthermore, Schaubroeck and Fink (1998) suggested paying attention to the interaction between job control and social support at work on work performance and well-being, as one reason of the inconsistent findings in tests of the DC model.

The aims of this study

To our knowledge, few studies have examined explicitly and specifically the synergistic interaction effect between job control and social support at work on common mental disorder and its dependence on the level of job demands in both male and female workers. Some investigators (Johnson and Hall 1988; Landsbergis et al. 1992) reported synergistic effects between job control and social support at work on cardiovascular diseases and job dissatisfaction when job demand was low, but the synergistic effects were not observed when job demand was high. The combination (i.e., called 'resources') of low job control, low social support at work, and low job rewards was a strong predictor for 
depression and anxiety in a subsample $(n=85)$ of the Whitehall II Study, while none of the risk factors examined separately was a significant predictor for depression and anxiety (Griffin et al. 2007). The Hordaland Health Study (Sanne et al. 2005a) implied, albeit not tested, a synergistic interaction between job control and social support at work for depression and anxiety in both men and women when the level of job demands was high.

In this study, we investigated a synergistic interaction effect between job control and social support at work on general psychological distress using a large Swedish male and female working population from the Malmö Shoulder and Neck Study (MSNS) (Östergren et al. 2005).

\section{Materials and methods}

\section{Design and population}

For this cross-sectional study, 1,035 male and 905 female workers (Table 1) were chosen from the MSNS cohort who completed both the baseline and follow-up MSNS questionnaires. The MSNS cohort consists of men and women, residing in the city of Malmö (240 000 inhabitants), Sweden, who were between 45 and 65 years of age in 1991, and who were recruited into the larger Malmö Diet and Cancer Study (MDCS) (Manjer et al. 2001) from February 1992 to December 1994. The cohort was recruited during the major political and financial crisis period of the Swedish society, for instance, unemployment rate dramatically increased from $1.7 \%$ in 1990 to $9.4 \%$ in 1994 (OECD 2006). Comparison with a public health survey (Lindström et al. 2001), covering $74.6 \%$ of the same age cohort, suggests that the MDCS population sample was selected toward better health than in the general population (Manjer et al. 2001). The participants in the original MDCS $(n=14,555$; participation rate, $40.8 \%)$ filled in a baseline $\left(T_{1}\right)$ questionnaire. After about 1 year (mean follow-up time, 403 days; standard deviation, 49), a follow-up $\left(T_{2}\right)$ questionnaire was mailed to the baseline participants. The follow-up questionnaire was returned by 12,607 men and women. Non-respondents were younger, less educated, and than respondents, but there were no gender differences between respondents and non-respondents.

Unfortunately, information on general psychological distress was not measured in the baseline study so it was not possible to perform a longitudinal analysis. For this cross-sectional study, we first excluded those with any of the following conditions at follow-up: the persons whose position or occupation was changed substantially during the
Table 1 Distributions of sociodemographic variables, psychosocial work characteristics, and psychological distress (GHQ case) in the Swedish male $(n=1,035)$ and female $(n=905)$ workers

$C$ job control, $D$ job demands, $S$ social support at work.

$* p<0.05 ; * * p<0.01$ when compared by repeated measures $t$-tests with values at $T_{1}$

\begin{tabular}{|c|c|c|c|}
\hline Variables & Category & $\operatorname{Men}(\%)$ & Women $(\%)$ \\
\hline \multirow[t]{2}{*}{ Age (years) } & $45-54$ & 61.0 & 62.8 \\
\hline & $55-64$ & 39.0 & 37.2 \\
\hline \multirow[t]{2}{*}{ Education (years) } & Up to 12 & 70.6 & 68.4 \\
\hline & Over 12 & 29.4 & 31.6 \\
\hline \multirow[t]{2}{*}{ Marital status } & Married & 75.9 & 62.8 \\
\hline & Non-married & 24.1 & 37.2 \\
\hline \multirow[t]{2}{*}{ Origin of country } & Swedish & 92.8 & 93.4 \\
\hline & Non-Swedish & 7.2 & 6.6 \\
\hline \multirow[t]{3}{*}{ Cross-sectional (at $T_{1}$ ) } & Low job control & 30.5 & 46.6 \\
\hline & High job demands & 51.2 & 45.9 \\
\hline & Low social support at work & 50.4 & 44.9 \\
\hline \multirow[t]{3}{*}{ Cross-sectional (at $T_{2}$ ) } & Low job control & $33.8 *$ & $55.2 * *$ \\
\hline & High job demands & $55.2 *$ & 48.8 \\
\hline & Low social support at work & 49.8 & $49.6 * *$ \\
\hline \multirow[t]{2}{*}{ Cross-time (both at $T_{1}$ and $T_{2}$ ) } & $\begin{array}{l}\text { Consistent } \mathrm{C}, \mathrm{D} \\
\text { and } \mathrm{S} \text { across times }\end{array}$ & 46.8 & 44.8 \\
\hline & $\begin{array}{l}\text { Changed C, D, } \\
\text { or S across times }\end{array}$ & 53.2 & 55.2 \\
\hline Family-to-work conflict (at $T_{2}$ ) & & 10.7 & 18.5 \\
\hline Stress from outside-work problems (at $T_{2}$ ) & & 20.5 & 31.6 \\
\hline Worry due to family members (at $T_{2}$ ) & & 7.5 & 21.0 \\
\hline \multirow[t]{2}{*}{ Number of days on sick leave (at $T_{2}$ ) } & $\leq 3$ days & 87.1 & 79.2 \\
\hline & $\geq 4$ days & 12.9 & 20.8 \\
\hline GHQ case (at $T_{2}$ ) & & 11.2 & 19.4 \\
\hline
\end{tabular}


follow-up, who worked less than $30 \mathrm{~h}$ per week, who were on a sick leave, or who did not have valid information on the mental health, psychosocial work characteristics, family-to-work conflict, stress from outside-work, and worry due to family members (see below). Thus 4,667 workers (2,324 men and 2,343 women) at follow-up were initially selected for this study. Second, we further restricted study subjects to those (4,236 workers: 2,159 men and 2,077 women) at follow-up who had been also vocationally active at baseline in order to assure work exposures between $T_{1}$ and $T_{2}$. In detail, the persons with any of the following characteristics at baseline were excluded: persons 65 years old or older, persons who worked less than $30 \mathrm{~h}$ per week, persons who were on long time ( $>1$ year) sick leave, or whose information about psychosocial work characteristics were missing. Third, we additionally excluded 2,296 workers (1,124 men and 1,172 women) at follow-up who had been relatively unhealthy at baseline as a way to remove possible impact of poor health status at $T_{1}$ on the association between psychosocial work characteristics and general psychological distress at $T_{2}$ : those who had had shoulder, neck, or lumbar pain 'often' or 'all the time' during the previous 12 months; who had been treated for any of the following chronic diseases: myocardial infarction, stroke, claudicatio intermittens, high blood pressure, diabetes mellitus, goiter, gastric ulcer, cancer, asthma, rheumatoid arthritis, inflammatory bowel disease, and renal calculi; or whose self-rated health (Eriksson et al. 2001) at baseline was poor-measured by one question ("How do you feel right now, physically and mentally, considering your health and wellbeing"), with seven response options from very bad to very good (the first three options were categorized into "poor" self-rated health). Several investigators (Bongers et al. 1993; Hotopf et al. 1998; Stansfeld et al. 1993) have reported the comorbidity between physical and mental illnesses and their bidirectional causality.

The final study subjects of this study were selected from the above three procedures: 1,940 workers $(1,035$ men and 905 women) at follow-up who had been relatively healthy at baseline. There were no substantial differences in age and sex between the relatively healthy workers $(n=1,940)$ and unhealthy workers $(n=2,296)$. However, the unhealthy group of workers was significantly less educated than the healthy group of workers. To see the impact of the above third procedure on study results, we also conducted analyses with the 4,236 workers (called alternative study group 1) including both the relative healthy and unhealthy groups of workers and only with the relatively unhealthy group of workers ( $n=2,296$; called alternative study group 2 ).

\section{Outcome variable at follow-up}

The 30-item version of the General Health Questionnaire, an instrument developed as a screening tool for detecting non-psychotic psychiatric illness (Goldberg 1972), was used to assess common mental disorders at follow-up. Each item has four response options such as "better than usual," "the same as usual," "less than usual," and "much less than usual." The items were scored using the "GHQ-scoring" method (0-0-1-1) and the standard threshold score of $\geq 5$ was used to define the GHQ case, in this paper labeled general psychological distress. In addition, a continuous scale for the GHQ-30 was created based on the original response category (1-2-3-4) for a simple correlation analysis (see Table 2) and its reliability was high (Cronbach alphas, 0.91 and 0.94 for men and women, respectively).

Exposure variables: psychosocial work characteristics

Job control and psychological job demands were assessed at both $T_{1}$ and $T_{2}$ by a Swedish version (Sanne et al. 2005b) of the Job Content Questionnaire (JCQ) (Karasek et al. 1985). Job control and psychological job demands scales were composed of six and five items, respectively, to which the individuals replied on a four-Likert-type response set (i.e., never to often). For the JCQ equivalent

Table 2 Spearman correlation coefficients between psychosocial work characteristics and psychological distress (at $T_{2}$ ) in the Swedish male $(n=1,035$; below the diagonal) and female $(n=905$; above the diagonal) workers

\begin{tabular}{lllrrr}
\hline Variables & $M(\mathrm{SD})^{\mathrm{a}}$ & $M(\mathrm{SD})^{\mathrm{b}}$ & \multicolumn{2}{l}{ Spearman correlation $(\gamma)$} \\
\cline { 3 - 6 } & & & 1 & 2 & \multicolumn{2}{c}{3} \\
\hline 1. Job control $\left(T_{2}\right)$ & $76.3(10.4)$ & $71.9(11.0)$ & & .05 & .14 \\
2. Psychological job demands $\left(T_{2}\right)$ & $32.3(6.4)$ & $31.3(6.6)$ & .18 & -.22 \\
3. Social support at work $\left(T_{2}\right)$ & $12.7(4.5)$ & $13.0(4.0)$ & .08 & -.16 & .16 \\
4. Psychological distress: GHQ-30 $\left(T_{2}\right)$ & $52.3(7.3)$ & $54.5(9.8)$ & -.15 & .16 & -.18 \\
\hline
\end{tabular}

$M$ mean, $S D$ standard deviation

${ }^{\text {a }}$ Men

b Women

$p<.05(|\gamma| \geq .07) ; p<.01(|\gamma| \geq .09) ; p<.001(|\gamma| \geq .11)$ 
scores, comparability-facilitating algorithms from a specific population-based comparative study (Karasek et al. 2007) were applied to the original two scales. The converted job control (Cronbach alphas, 0.66-0.69 for men and women) and job demands (Cronbach alpha, 0.70-0.74 for men and women) scales at both $T_{1}$ and $T_{2}$ were then dichotomized into high and low job control and demands, respectively, at their baseline means in a larger MSNS population ( $n=7,130$; age 45-64, working more than $30 \mathrm{~h}$, and sicklisted less than 1 year). Social support at work (Cronbach alphas, 0.91-0.90 for men and women) was measured at both $T_{1}$ and at $T_{2}$ by the six standard items about coworker and supervisor support in the Swedish version of the JCQ (Sanne et al. 2005b). The six-item scale was additionally dichotomized (high vs. low) at its mean for analyses.

Only 484 of 1,035 (46.8\%) men and 405 of 905 (44.8\%) women had a consistent exposure history of all of the three psychosocial work characteristics between $T_{1}$ and $T_{2}$, for instance, high job control, low job demands, and high social support at work at both $T_{1}$ and $T_{2} ; 53.2 \%$ of men and $55.2 \%$ of women had a changed exposure history of at least one of the three psychosocial work characteristics between $T_{1}$ and $T_{2}$, for instance, high job control and low job demands at both $T_{1}$ and $T_{2}$, but high social support at work only at $T_{1}$ (and low social support at $T_{2}$ ). The history of the three psychosocial work characteristics (i.e., consistent vs. changed) was considered as a covariate in multivariate logistic regression analysis (see below).

\section{Socio-demographic and other covariates}

Age at baseline was considered for analyses. The classification of country of origin at baseline consisted of a simple dichotomy between individuals born in Sweden and those born in other countries. Marital status at baseline was used as a dichotomous variable (married and others: unmarried, divorced, or widowed). Education level at baseline was determined by the self-reported total years of formal education used in the analyses as a dichotomous variable (up to 12 and $>12$ years). The total number of days on sick leave during the last 12 months was measured at follow-up by one question. It was then divided into two groups ( $\leq 3$ and $\geq 4$ days) for analysis. Family-to-work conflict was measured at follow-up by four questions (eg. "family worries or problems distract you from your work") (Chandola et al. 2004). Family-to-work conflict scores ranged between 4 (no conflict whatsoever) and 12 (maximum conflict). The distribution shape of the scores was skewed so the scores were dichotomized for analysis at 6 points. Stress from outside-work demands/problems at follow-up was measured by one question (yes or no). Worry due to family members (eg. parents, parents-in-law, etc.) at follow-up was measured by one question on a five-Likert-type response set (always to never). The highest two responses (always and often) were summed up for defining the group of "worry due to family' in this study.

\section{Statistical methods}

The relationships between the psychosocial work characteristics and psychological distress were first examined by Spearman correlation coefficients. The proportion changes of low job control, high job demands, and low social support at work between $T_{1}$ and $T_{2}$ were compared by paired (repeated measures) $t$-tests. At first, heuristically, the independent effects of the psychosocial work characteristics (at $T_{2}$ ) on general psychological distress (at $T_{2}$ ) were investigated through a series of multivariate logistic regression analyses (Model 1: only with the three psychological work characteristics; Model 2: additionally with age, marital status, origin of country, and education; and Model 3: additionally with age, marital status, origin of country, education, family-to-work conflict, stress from outsidework problems, worry due to family members, number of days on sick leave, and the history of the psychosocial work characteristics).

Then, the synergistic interaction effect of job control and social support at work on general psychological distress was investigated after creating three dummy variables for the following four $(2 \times 2)$ conditions: High control and High support (the reference condition); High control but Low support; Low control but High support; and Low control and Low support. The foci of the examinations were whether the effects of the three non-reference working conditions on general psychological distress were significant and whether they were consistent with the results under the above no-interaction model. Then quantitatively, synergistic interaction was evaluated to be present if the effect of the combination of the both exposures was more than additive (synergy index, $S>1$, see Fig. 1) (Rothman 1986), compared to their independent effects. Antagonistic interaction was defined as $S<1$ (Rothman 1986). The confidence interval (CI) of synergy index was estimated with the method (Hosmer and Lemeshow 1992). An asymptotic covariance matrix, generated by the SPSS syntax (Andersson et al. 2005) was used for the calculation of the standard error of synergy index. In order to avoid a potential Type II error, not unusual in interaction tests (Greenland 1993; Marshall 2007; Selvin 1996), we calculated not only 95\% CIs but also $80 \%$ CIs of synergy indexes. The analysis was carried

$$
S=\frac{O R(A B)-1}{[O R(A b)-1]+[O R(a B)-1]}
$$

Fig. 1 Synergy index $(S)$ : $O R$ odds ratio, $A b$ exposed to one factor, $a B$ exposed to the other factor, $A B$ exposed to both factors 
out separately for men and women, considering potential gender-specific associations of psychosocial work characteristics on mental health (Bildt and Michélsen 2002; Clays et al. 2007). As a sensitivity test, all of the above multivariate analyses were replicated in the two alternative study groups, after an additional adjustment for the health conditions at baseline (musculoskeletal disorder, chronic diseases, and self-reported health).

\section{Results}

Descriptive statistics and correlations

General psychological distress (GHQ case) is more prevalent in women $(19.4 \%)$ than in men (11. 2\%). Job control and job demands were higher in male workers at both $T_{1}$ and $T_{2}$, but social support was higher in female workers at $T_{1}$ (Table 1). On average, the psychosocial work characteristics of the male and female workers were deteriorated during the follow-up period. Particularly, job control decreased and job demands increased in male workers, while job control and social support at work decreased significantly $(p<0.01)$ in female workers. Table 2 shows that all of the zero-order Spearman correlations of job control, job demands, and social support at work at follow-up with general psychological distress at follow-up are significant $(p<0.01)$, and they are relatively stronger in women than in men. Social support at work was positively correlated with job control, but negatively associated with psychological job demands for both men and women.

Independent effect of each of the psychosocial work characteristics?

First, we conducted a series of multivariate logistic regression analyses under an assumption of no interaction effects between the psychosocial work characteristics (Table 3). After controlling for socio-demographic, history of psychosocial work characteristics, and other covariates, social support at work (at $T_{2}$ ) was associated with general psychological distress in men. Low job control and high psychological job demands were only marginally $(p<0.10)$ associated with general psychological distress in men. In women, low job control and low social support at work were associated with general psychological distress in women, while high psychological job demand did not increase the risk for general psychological distress.

On the other hand, family-to-work conflict and stress from outside-work demands for both men and women and marital status (being non-married) for women were significant risk factors for general psychological distress (Table 3). Age, origin of country, low education, worry for family member, number of sick days, and history of the psychosocial work characteristics (changed vs. consistent) did not affect the above associations.

Table 3 Odds ratios of job control, job demands, and social support at work for general psychological distress in multivariate logistic regression models

\begin{tabular}{|c|c|c|c|c|c|c|}
\hline \multirow[t]{2}{*}{ Variables } & \multicolumn{3}{|l|}{$\operatorname{Men}(n=1,035)$} & \multicolumn{3}{|l|}{ Women $(n=905)$} \\
\hline & Model 1 & Model 2 & Model 3 & Model 1 & Model 2 & Model 3 \\
\hline Low job control & $1.43(0.96-2.14)$ & $1.41(0.93-2.14)$ & $1.47(0.94-2.30)$ & $1.44(1.01-2.05)$ & $1.64(1.13-2.38)$ & $1.88(1.25-2.83)$ \\
\hline High job demands & $1.71(1.13-2.60)$ & $1.75(1.15-2.65)$ & $1.47(0.95-2.30)$ & $1.51(1.08-2.13)$ & $1.42(1.00-2.01)$ & $1.06(0.72-1.55)$ \\
\hline Low social support at work & $1.72(1.15-2.59)$ & $1.71(1.14-2.58)$ & $1.61(1.04-2.48)$ & $2.23(1.56-3.19)$ & $2.16(1.50-3.10)$ & $2.08(1.41-3.07)$ \\
\hline Age (vs. $45-54$ years old) & & $1.18(0.79-1.76)$ & $1.40(0.91-2.16)$ & & $0.64(0.44-0.92)$ & $0.76(0.51-1.15)$ \\
\hline Marital status (vs. married) & & $1.48(0.96-2.28)$ & $1.33(0.84-2.11)$ & & $1.29(0.91-1.83)$ & $1.54(1.05-2.26)$ \\
\hline Origin of country (vs. Swedish) & & $0.99(0.46-2.15)$ & $0.80(0.34-1.87)$ & & $1.83(1.01-3.31)$ & $1.75(0.89-3.41)$ \\
\hline Low education (vs. >12 years) & & $0.95(0.61-1.47)$ & $1.20(0.75-1.93)$ & & $0.66(0.46-0.97)$ & $0.73(0.48-1.09)$ \\
\hline Family-to-work conflict & & & $2.75(1.61-4.70)$ & & & $2.28(1.46-3.57)$ \\
\hline $\begin{array}{l}\text { Stress from outside-work } \\
\text { problems }\end{array}$ & & & $4.60(2.95-7.17)$ & & & $4.50(3.01-6.73)$ \\
\hline Worry due to family members & & & $1.20(0.63-2.31)$ & & & $1.52(0.98-2.37)$ \\
\hline $\begin{array}{l}\text { Number of days on sick } \\
\text { leave (vs. } \leq 3 \text { days) }\end{array}$ & & & $1.53(0.87-2.69)$ & & & $1.10(0.70-1.71)$ \\
\hline $\begin{array}{l}\text { Changed psychosocial } \\
\text { work characteristics } \\
\text { (vs. consistent } \\
\text { between } T_{1} \text { and } T_{2} \text { ) }\end{array}$ & & & $1.02(0.67-1.56)$ & & & $0.92(0.63-1.34)$ \\
\hline
\end{tabular}


Synergistic interaction effects of job control and social support at work

Next, we examined the synergistic effect between job control and social support at work on general psychological distress. As expected, the prevalence of general psychological distress was highest among workers who have low job control and low social support at work and lowest among workers who have high control and high social support at work in both men and women (Table 4). After adjustment for job demands, history of psychosocial work characteristics, socio-demographic and other covariates, neither low job control nor low social support at work was a risk factor for general psychological distress in men as long as social support at work or job control is high, respectively. Low job control was not a risk factor for general psychological distress in women as long as social support at work was high. The risk for general psychological distress increased significantly in both men and women when workers had both low job control and low social support at work (Table 4). The combined risk of low control and low social support at work was 2.37 (137\% excessive risk) in male workers, and 3.78 (278\% excessive risk) in female workers. Synergy indexes between job control and social support at work were 1.68 and 1.83 in men and women, respectively. Their $95 \%$ and $80 \%$ CIs included unity in both men and women, except for the $80 \%$ CI (1.26-2.65) in women. The excessive risks were greater than what could be intuitively estimated from the multivariate regression models under the additive assumption (i.e., Table 3 ) between the psychosocial work characteristics: $108 \%$ (i.e., $47 \%$ from low job control and $61 \%$ from low social support at work) excessive risk in male workers and $196 \%$ excessive risk in female workers. Job demand was not associated with general psychological distress in both men and women (data not shown here).
Impact of job demands on the synergistic effects

The synergistic interaction effect between job control and social support at work was reexamined with stratification for the level of job demands through multivariate logistic regression analysis in order to examine the impact of job demands on the synergetic effects. In men, the risk of the combination of low job control and low social support at work for psychological distress increased only when workers had low job demands. The synergistic effect between job control and social support at work on general psychological distress became stronger $(S=9.25 ; 80 \%$ $\mathrm{CI}=0.95-89.68)$ in male workers who had low job demands (Table 5). However, there was an antagonistic interaction effect $(S=0.49 ; 80 \% \mathrm{CI}=0.26-1.02)$ between job control and social support at work in the high job demands group of male workers. In female workers, increased risks of the combination of low job control and low social support at work for general psychological distress were observed, regardless of the level of job demands. The synergistic effect was slightly stronger when the level of job demands was low $(S=2.16 ; 80 \% \mathrm{CI}=1.16-4.03)$ than when the level of job demand was high $(S=1.51 ; 80 \%$ $\mathrm{CI}=1.00-2.28$ ).

Additionally, the risk of the eight (i.e., $2 \times 2 \times 2$ ) combinations between job control, job demands, and social support at work (as the reference group with high job control, low job demands, and high social support at work) for general psychological distress was examined. Table 5 (i.e., last column) shows that the combination of low job control and low social support at work is a risk factor for general psychological distress (ORs, 2.99-3.82 for men and 3.49-3.66 for women) in both men and women. In male workers, the risk was higher in the two groups (low job control, low job demands, and low social support at work; low job control, high job demands, and high social support at work) than in

Table 4 Synergistic interaction effects between job control and social support at work on general psychological distress in the Swedish male $(n=1,035)$ and female $(n=905)$ workers

\begin{tabular}{|c|c|c|c|c|c|c|}
\hline \multirow[t]{3}{*}{ Sex } & \multirow[t]{3}{*}{ Job control } & \multicolumn{2}{|c|}{ GHQ case, $\%(n)$} & \multicolumn{2}{|c|}{ Odds ratio $(95 \% \mathrm{CI})^{\mathrm{a}}$} & \multirow[t]{3}{*}{ Synergy index $(95 \% \mathrm{CI} ; 80 \% \mathrm{CI})$} \\
\hline & & \multicolumn{2}{|c|}{ Social support at work } & & & \\
\hline & & High & Low & & & \\
\hline \multirow[t]{2}{*}{ Men } & High & $7.8(371)$ & $12.4(314)$ & 1.00 & $1.50(0.88,2.58)$ & \\
\hline & Low & $8.7(149)$ & $17.4(201)$ & $1.31(0.63,2.71)$ & $2.37(1.34,4.18)$ & $1.68(0.36-7.77 ; 0.90-3.15)$ \\
\hline \multirow[t]{2}{*}{ Women } & High & $10.9(247)$ & $22.2(158)$ & 1.00 & $1.85(1.02,3.37)$ & \\
\hline & Low & $14.4(209)$ & $28.9(291)$ & $1.67(0.90,3.09)$ & $3.78(2.21,6.46)$ & $1.83(0.74-4.52 ; 1.25-2.65)$ \\
\hline
\end{tabular}

CI confidence interval

a Psychological job demands, consistent and changed history of psychosocial work characteristics, age, education, origin of country, marital status, family-to-conflict, number of days on sick leave, stress from outside-work problems, and worry due to family members were all controlled for 
the iso-strain group (high job strain and low social support at work), which was not in line with the prediction of the demand-control-support model. Although the simple prevalence rate of general psychological distress was highest in the iso-strain group, it was not when the family-to-work conflict and stress from outside-work problems variables were entered in the multivariate analyses. In female workers, the highest risk for general psychological distress was found in the iso-strain group as predicted by the demandcontrol-support model, however, its effect size $(\mathrm{OR}=3.66)$ was close to that $(\mathrm{OR}=3.49)$ of the group with low job control, low social support at work, and low job demands: the family-to-work conflict and stress from outside-work problems variables narrowed the risk difference between the two groups in the multivariate analyses. The two combinations (high job demand and low social support at work; low job control and high job demands) did not increase the risk for general psychological distress in female workers as long as job control or social support at work was high, respectively.

Sensitivity tests in two alternative groups

Sensitivity tests were conducted in the two alternative study groups to see whether the unhealthy workers at baseline, excluded from the study subjects of this study, made a difference in the above results. The sensitivity analyses were the same as the above multivariate analyses (Tables 3, 4 and 5), except that they were conducted additionally after adjustment of the health conditions at baseline. In the two alternative study groups, the three unhealthy conditions, such as musculoskeletal disorder, chronic diseases, and self-reported poor health, were more strongly associated with psychological distress in women than in men (data not shown here).

In men, the results of the sensitivity analyses in the larger sample (i.e., alternative study group $1, n=4,236$ ) were generally similar to those in the above multivariate analyses. For instance, a synergistic effect of low job control and low social support at work on psychological distress was observed only when job demands were low (Table 6), although its synergy index decreased to 5.88 (80\% CI $=1.31-26.43$ ). However, the combination of low job control and low social support at work was a significant risk factor for psychological distress even when job demands were high, which was different from the result only with the relatively healthy workers (i.e., Table 5). In women, the combination of low job control and low social support at work was still a significant risk factor for psychological distress, regardless of the level of job demands, but its effect sizes decreased substantially. For example, the synergy indexes were 1.16 (in the low job demands group) and 1.04 (in high job demands group) and their $80 \%$ CIs included unity (Table 6). 


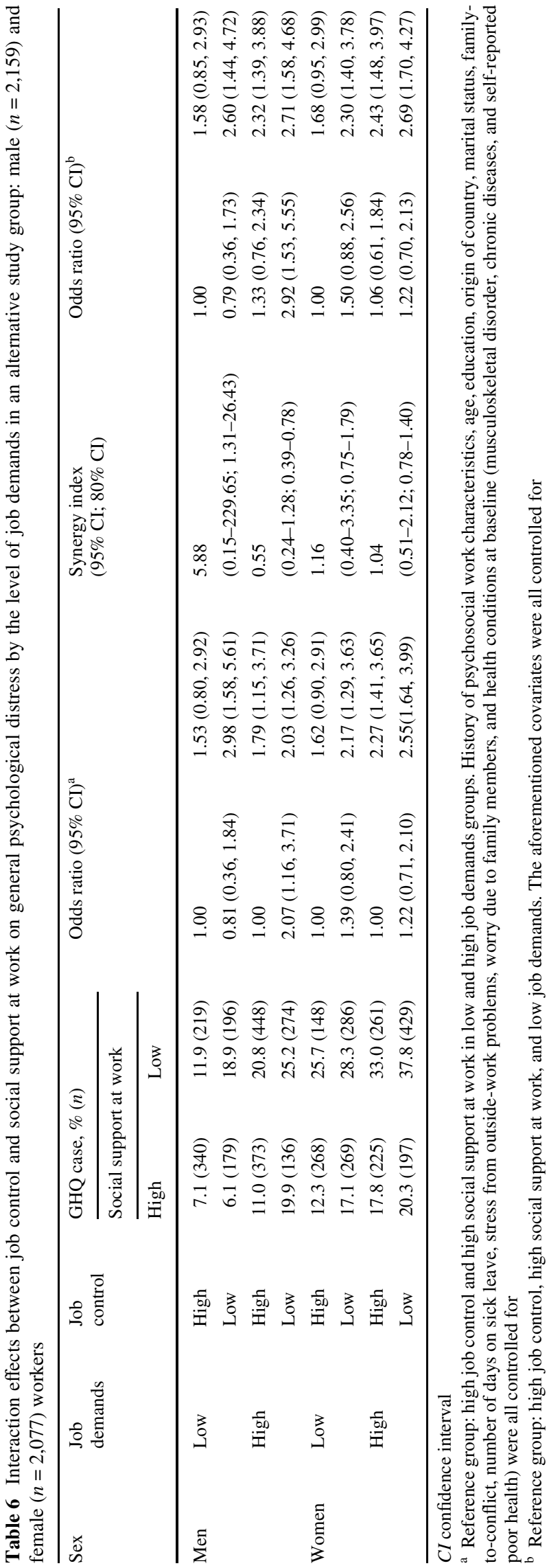

The results of the sensitivity analyses in the relatively unhealthy sample (i.e., alternative study group $2, n=2,296$ ) were different, particularly in women, from those in the relatively healthy sample (i.e., study subjects of this study). In men, the combination of low job control and low social support at work was a significant risk factor for psychological distress, regardless of the level of job demands. The synergy indexes ( $80 \%$ CIs) between job control and social support at work in men were $2.76(0.70-10.93)$ when job demands were low and $0.62(0.43-0.91)$ when job demands were high. In women, they were $0.76(0.35-1.64)$ and 0.79 (0.53-1.18), respectively. The combination of low job control and low social support at work was a significant risk factor for psychological distress only when job demands were high.

\section{Discussion}

This cross-sectional study supported partially in men and fully in women a synergistic interaction effect between job control and social support at work on general psychological distress, which was hypothesized based on the collective control concept. A significant excessive risk increase for general psychological distress was observed when workers had both low job control and low social support at work in both men and women when the level of job demands was low. However, the synergistic effect was affected by high job demands differently by gender. In women, the synergistic effect was maintained, but attenuated to some extent when the level of job demands was high. In men, an antagonistic effect between job control and social support at work was observed when the level of job demands was high.

Comparisons with other studies

To our knowledge, this is one of the few studies explicitly testing and reporting a synergistic interaction between job control and social support at work on common mental disorders in a large male and female working population from diverse occupations and industries. This study was consistent with the previous study (Sanne et al. 2005a) in that a synergistic effect was found between job control and social support at work on common mental disorders, and the synergistic effect was found in female workers, regardless of the level of job demands. However, this study is in contrast with the Norwegian study (Sanne et al. 2005a) in terms of the direction of the impact of job demands on the synergistic effect. In this study, the synergistic effect was found in male workers only when the level of job demands was low, but it was found only when the level of job demands was high in the Norwegian study (Sanne et al. 2005a). In this 
study, the synergistic effect was stronger in female workers when the level of job demands was low, but it was stronger oppositely when the level of job demands was high in the Norwegian study (Sanne et al. 2005a). These patterns indicate that if any, a synergistic interaction effect between job control and social support at work on common mental disorders might vary by the level of job demands, gender, and study context (eg. in a Swedish economic crisis for this study).

The minor impact of "high" job demands on the synergistic effect in female workers might be explained by the fact that during the follow-up period of this study cohort, on average, job demands of female workers did not change much, while job control and social support at work were deteriorated significantly. Under this situation, the critical factors for mental health of female workers would be resources rather than the level of job demands. The antagonistic interaction between job control and social support at work in male workers under high job demands was an unexpected finding. This may suggest that high social support at work could be a stressor rather than a stress reducer under a special circumstance (House 1981; Karasek et al. 1982; Vanroelen et al. 2009; Westman et al. 1985), for instance, when a worker in a team with strong internal solidarity is pressured to provide the same or perhaps increased level of socio-emotional social support to other coworkers given his/her significant job changes (eg. increased job strain). In fact, on average, job control and job demands of male workers were deteriorated (i.e., increased job strain) during the follow-up, while social support at work did not change much. However, this quantitative study did not allow us to test the aforementioned context-specific explanations.

\section{Methodological issues}

In this study, we excluded the relatively unhealthy workers at baseline from the study subjects of this study. The results of the sensitivity tests in the two alternative study groups supported the validity of the decision, despite a loss of statistical power. Including them into study subjects of this study (alternative study group 1) would have significantly underestimated the synergistic effects between job control and social support at work in both men and women. At the same time, the results in the group (Table 6) suggests that a statistical adjustment of the baseline health conditions was not enough to remove their impact on the psychological job characteristics and general psychological distress at follow-up.

We reported the two (80 and 95\%) CIs of the Rothman's synergy index in consideration of a potential Type II error. In this study, all of the synergy indexes between job control and social support at work on psychological distress were non-significant at the alpha level of 0.05 . However, they were significant at the alpha level of 0.20 in women (Tables 4, 5). Also, in men, when the sample size was almost doubled (i.e., in the alternative study group 1), the $80 \%$ CIs of the synergistic indexes became clearly above or below unity (Table 6). All of these indicate that an injudicious application of the typical alpha level (0.05) to interaction significance tests could obscure a possible synergism. As mentioned before, low statistical power in interaction tests (Greenland 1993; Marshall 2007; Selvin 1996) should be considered. In addition, Rothman (1978) warned that a quantitative interval estimation of synergy index should not be confused with a significance test (in which typically the alpha level of 0.05 is employed). Hogan et al. (1978) also reported that the CIs of synergy index based on a simple asymptotic approach (Hosmer and Lemeshow 1992) could be unduly conservative in comparison with alternative approaches. More importantly, we think that a synergism between two exposures should be judged based on an array of information such as a strong theoretical hypothesis, a significant difference between the results under no-interaction assumption and under an interaction assumption as presented in Tables 3, 4 and 5, and confidence intervals considering a type II error, not solely based on the significance test (at the alpha of 0.05 ) of synergy index.

Implications for risk assessment, job stress models, and interventions

The most important lesson from this study is that the risk assessment of the combination of low job control, high job demands, and low social support at work on common mental disorders needs to be conducted with full consideration of their interactions and study context (Johnson and Hall 1996; Kasl 1996; Schaubroeck and Fink 1998). An atomic, additive approach to the risk assessment of the psychosocial work characteristics on common mental disorders could be misleading or lead to a risk underestimation. For example, in male workers of this study, neither low job control nor high job demand was significantly associated with general psychological distress when they were examined individually. But they were risk factors in combinations with low social support at work for general psychological distress. In addition, the combined risk of low job control and low social support at work were greater than the sum of their individual risks in both male and female workers.

On the other hand, this study raises a question about the robustness of contemporary job stress models such as the DR and DCS models in which the possibility of synergistic interactions between resources or between job control and social support at work is not considered. Ignoring such interactions could result in limited validity of such models in reality (Schaubroeck and Fink 1998). For example, the 
DC and DCS models were only partially supported in this study (see the last column of Table 5). The DC model (i.e., the highest risk in the low control and high job demand group) was supported in male workers only when social support at work was high (not when it was low) and in female workers only when social support at work was low (not when it was high). The DCS model (i.e., the highest risk in the group of low control, high job demand, and low social support) was supported only in female workers (not in male workers). Therefore, in accordance with the position of Kasl (1996) and Schaubroeck and Fink (1998), it would be desirable to examine and report all possible interactions between job control, job demands, and social support at work on mental disorders beyond the DCS modelprescribed interactions between job control and job demands and between job strain and social support at work, particularly when the primary goal of a research is to test the DC and DCS models. Such practice will be useful for testing and advancing the models in the future because it could provide richer information about when and why the models do or do not work in reality.

Also, this study has implications for psychosocial interventions to improve workers' mental health in an economic downturn. It suggests that a substantial deterioration of workers' mental health could be prevented by promoting either workers' task-level control or workers' internal solidarity or both (not necessarily both in women), even when the level of job demand is high. The management needs to adopt an internal work organization policy of empowering workers rather than depowering workers in an economic crisis for both workers' mental health and productivity (Appelbaum and Donia 2000).

\section{Limitations of this study}

This study as a cross-sectional, secondary analysis study has a limitation for withdrawing a strong causal inference about the synergistic interaction effect between job control and social support at work on common mental disorders. Nonetheless, this study has a merit over typical cross-sectional studies in that it initially restricted study subjects to relatively healthy and vocationally active workers at baseline. Thus, the directionality of the associations between psychosocial work characteristics and psychological distress in this study seems to be forward rather than backward (reversed causations). The second limitation of this study is related to the generalization of the results of this study. As noted before, the study subjects of this study were more older, highly educated, and healthier workers than the same age Malmo cohort. So the interpretations of the results in this study should be made in consideration of the aforementioned "selective" characteristics of study subjects. Also, a due attention should be paid to the fact that this study was conducted on Swedish workers in an economic downturn.
Therefore, it is limited as yet to generalize the findings of this study to other working populations in different cultures and/or economic situations. Nonetheless, as mentioned before, this study suggests an important work organization policy direction (empowering workers) for both workers' mental health and productivity in the global-scale economic recession of the late 2000s. More prospective studies in the future are warranted to shed light on the synergistic effect between job control and social support at work on common mental disorders and its relationship to job demands.

Acknowledgments This study was supported by grants from the Swedish Council for Social Research (FAS 2003-0582) and the Medical Faculty at Lund University (ALF-grant).

Conflict of interest statement The authors declare that they have no conflict of interest.

Open Access This article is distributed under the terms of the Creative Commons Attribution Noncommercial License which permits any noncommercial use, distribution, and reproduction in any medium, provided the original author(s) and source are credited.

\section{References}

Andersson T, Alfredsson L, Källberg H, Zdravkovic S, Ahlbom A (2005) Calculating measures of biological interaction. Eur J Epidemiol 20(7):575-579

Appelbaum SH, Donia M (2000) The realistic downsizing preview: a management intervention in the prevention of survivor syndrome (part I). Career Dev Int 5(7):333-350

Aronsson G (1989) Dimensions of control as related to work organization, stress, and health. Int J Health Serv 19:459-468

Beck DA, Koenig HG (1996) Minor depression: a review of the literature. Int J Psychiatry Med 26:177-209

Bildt C, Michélsen H (2002) Gender differences in the effects from working conditions on mental health: a 4-year follow-up. Int Arch Occup Environ Health 75:252-258

Bonde JP (2008) Psychosocial factors at work and risk of depression: a systematic review of the epidemiological evidence. Occup Environ Med 65:438-445

Bongers PM, de Winter CR, Kompier MA, Hildebrandt VH (1993) Psychosocial factors at work and musculoskeletal disease. Scand J Work Environ Health 19(5):297-312

Bültmann U, Kant IJ, van den Brandt PA, Kasl SV (2002) Psychosocial work characteristics as risk factors for the onset of fatigue and psychological distress: prospective results from the Maastricht Cohort Study. Psychol Med 32:333-345

Chandola T, Martikainen P, Bartley M, Lahelma E, Marmot M, Michikazu S, Nasermoaddeli A, Kagamimori S (2004) Does conflict between home and work explain the effect of multiple roles on mental health? A comparative study of Finland, Japan, and the UK. Int J Epidemiol 33:884-893

Clays E, De Bacquer D, Leynen F, Kornitzer M, Kittel F, De Backer G (2007) Job stress and depression symptoms in middle-aged workers-prospective results from the Belstress study. Scand J Work Environ Health 33:252-259

de Jonge J, Dormann C (2003) The DISC model: demand induced strain compensation mechanisms in job stress. In: Dollard MF, Winefield AH, Winefield HR (eds) Occupational stress in the service professions. Taylor \& Francis, London, pp 43-74 
Demerouti E, Bakker AB, Nachreiner F, Schaufeli WB (2001) The job demands-resources model of burnout. J Appl Psychol 86:499-512

Eriksson I, Undén AL, Elofsson S (2001) Self-rated health. Comparisons between three different measures. Results from a population study. Int J Epidemiol 30:326-333

Gardell B (1982) Scandinavian research on stress in working life. Int J Health Serv 12:31-41

Goldberg DP (1972) The detection of psychiatric illness by questionnaire: a technique for the identification and assessment of nonpsychotic psychiatric illness. Oxford University, London

Greenland S (1993) Basic problems in interaction assessment. Environ Health Perspect 101(Suppl 4):59-66

Griffin JM, Greiner BA, Stansfeld SA, Marmot M (2007) The effect of self-reported and observed job conditions on depression and anxiety symptoms: a comparison of theoretical models. J Occup Health Psychol 12:334-349

Grzyb GJ (1981) Decollectivization and recollectivization in the workplace: the impact of technology on informal work groups and work culture. Econ Ind Democr 2:455-482

Hogan MD, Kupper LL, Most BM, Haseman JK (1978) Alternatives to Rothman's approach for assessing synergism (or antagonism) in cohort studies. Am J Epidemiol 108(1):60-67

Hosmer DW, Lemeshow S (1992) Confidence interval estimation of interaction. Epidemiology 3(5):452-456

Hotopf M, Mayou R, Wadsworth M, Wessely S (1998) Temporal relationships between physical symptoms and psychiatric disorder. Results from a national birth cohort. Br J Psychiatry 173:255-261

House JS (1981) Work stress and social support. Addison-Wesley, Reading

Houtman I (2005) Work-related stress. Available via http://www.eurofound.europa.eu/pubdocs/2005/127/en/1/ef05127en.pdf. Accessed 1 Mar 2006

Johnson JV (1991) Collective control: strategies for survival in the workplace. In: Johnson JV, Johansson G (eds) The psychosocial work environment: work organization, democratization, and health: essays in memory of Bertil Gardell. Baywood, New York, pp 193-223

Johnson JV, Hall EM (1988) Job strain, work place social support, and cardiovascular disease: a cross-sectional study of a random sample of the Swedish working population. Am J Public Health 78:1336-1342

Johnson JV, Hall EM (1996) Dialectic between conceptual and causal inquiry in psychosocial work-environment research. J Occup Health Psychol 1(4):362-374

Karasek RA (1979) Job demands, job decision latitude, and mental strain: implications for job redesign. Admin Sci Quart 24:285-308

Karasek RA, Triantis K, Chaudhry S (1982) Co-worker and supervisor support as moderators of association between task characteristics and mental strain. J Occup Behav 3:147-160

Karasek RA, Gordon G, Pietrokovsky C, Frese M, Pieper C, Schwartz J et al (1985) Job content questionnaire and user's guide. University of Massachusetts, Lowell

Karasek RA, Choi B, Ostergren PO, Ferrario M, De Smet P (2007) Testing two methods to create comparable scale scores between the job content questionnaire (JCQ) and JCQ-like questionnaires in the European JACE Study. Int J Behav Med 14:189-201

Kasl SV (1996) The influence of the work environment on cardiovascular health: a historical, conceptual, and methodological perspective. J Occup Health Psychol 1:42-56

Landsbergis PA, Schnall PL, Deitz D, Friedman R, Pickering T (1992) The patterning of psychological attributes and distress by "job strain" and social support in a sample of working men. J Behav Med 15:379-405

Lindström M, Sundquist J, Östergren PO (2001) Ethnic differences in self reported health in Malmo in southern Sweden. J Epidemiol Community Health 55(2):97-103
Manjer J, Carlsson S, Elmståhl S, Gullberg B, Janzon L, Lindström M et al (2001) The Malmö Diet and Cancer Study: representativity, cancer incidence and mortality in participants and non-participants. Eur J Cancer Prev 10:489-499

Marchand A, Demers A, Durand P (2005) Does work really cause distress? The contribution of occupational structure and work organization to the experience of psychological distress. Soc Sci Med 61:1-14

Marshall SW (2007) Power for tests of interaction: effect of raising the Type I error rate. Epidemiol Perspect Innov 4:4

National Institute for Occupational Safety and Health (2004) Worker health chartbook 2004. NIOSH Publication No. 2004-146. NI$\mathrm{OSH}$, Cincinnati

Netterstrøm B, Conrad N, Bech P, Fink P, Olsen O, Rugulies R, Stansfeld S (2008) The relation between work-related psychosocial factors and the development of depression. Epidemiol Rev 30:118-132

Niedhammer I, Goldberg M, Leclerc A, Bugel I, David S (1998) Psychosocial factors at work and subsequent depressive symptoms in the Gazel cohort. Scand J Work Environ Health 24:197-205

Organization for Economic Cooperation and Development (2006) OECD factbook 2006: economic, environmental and social statistics. OECD, Paris

Östergren PO, Hanson BS, Balogh I, Ektor-Andersen J, Isacsson A, Orbaek $P$ et al (2005) Incidence of shoulder and neck pain in a working population: effect modification between mechanical and psychosocial exposures at work? Results from a one year follow up of the Malmö shoulder and neck study cohort. J Epidemiol Community Health 59:721-728

Rothman KJ (1978) Estimation versus detection in the assessment of synergy. Am J Epidemiol 108(1):9-11

Rothman JK (1986) Modern epidemiology. Little, Brown and Company, Boston

Sanne B, Mykletun A, Dahl AA, Moen BE, Tell GS (2005a) Testing the job demand-control-support model with anxiety and depression as outcomes: the Hordaland Health Study. Occup Med 55:463-473

Sanne B, Torp S, Mykletun A, Dahl AA (2005b) The Swedish demand-control-support questionnaire (DCSQ): factor structure, item analyses, and internal consistency in a large population. Scand J Public Health 33:166-174

Schaubroeck J, Fink LS (1998) Facilitating and inhibiting effects of job control and social support on stress outcomes and role behavior: a contingency model. J Organ Behav 19:167-195

Schaufeli W, Kompier MAJ (2001) Managing job stress in The Netherlands. Int J Stress Manag 8:15-34

Selvin S (1996) Statistical analysis of epidemiologic data. Oxford University, Oxford, pp 213-214

Stansfeld S, Candy B (2006) Psychosocial work environment and mental health - a meta-analytic review. Scand J Work Environ Health 32:443-462

Stansfeld SA, Smith GD, Marmot M (1993) Association between physical and psychological morbidity in the Whitehall II Study. J Psychosom Res 37(3):227-238

Stansfeld SA, Bosma H, Hemingway H, Marmot MG (1998) Psychosocial work characteristics and social support as predictors of SF36 health functioning: the Whitehall II study. Psychosom Med 60:247-255

Stansfeld SA, Fuhrer R, Shipley MJ, Marmot MG (1999) Work characteristics predict psychiatric disorder: prospective results from the Whitehall II Study. Occup Environ Med 56:302-307

Thompson WD (1991) Effect modification and the limits of biological inference from epidemiologic data. J Clin Epidemiol 44:221-232

Vanroelen C, Levecque K, Louckx F (2009) Psychosocial working conditions and self-reported health in a representative sample of wage-earners: a test of the different hypotheses of the 
Demand-Control-Support-Model. Int Arch Occup Environ Health 82:329-342

Wang JL, Pattern SB (2004) Perceived work stress and major depressive episodes in a population of employed Canadians over 18 years of age. J Nerv Ment Dis 192:160-163
Westman M, Eden D, Shirom A (1985) Job stress, cigarette smoking and cessation: the conditioning effects of peer support. Soc Sci Med 20:637-644 